\title{
Climate change, health, and penguins in Copacabana
}

There is growing evidence that the planet's climate is changing at a pace and level never before witnessed by humankind. The concentration of $\mathrm{CO}_{2}$ in the atmosphere is unprecedented, temperatures are increasing practically all over the planet, the polar icecaps are melting, and the ocean levels are rising ${ }^{1}$. From the thermodynamic point of view, the increase in the atmosphere's temperature involves an enormous accumulation of heat that tends to intensify energy exchanges between land, ocean, and atmosphere 2 , producing extreme climate events like droughts, floods, and heat waves.

Yet the consequences of these phenomena for health are not obvious, direct, or immediate. While climate change can produce extreme, unexpected, and sometimes catastrophic events, an unusual event is not necessarily the result of climate change. The appearance of penguins on Copacabana Beach in Rio de Janeiro can be viewed as one such unusual event, although frequent. In fact, some penguins come to Rio de Janeiro's beaches during the winter in search of food, following ocean currents after splitting away from their colonies. The increasing appearance of penguins in Copacabana, out-of-season and in larger numbers, may point to new migratory patterns and a possible food shortage in the South Seas or changing patterns in coastal currents. However, in order to be considered an indicator of climate change, the event must be related to a broader, global process, although manifested locally. In addition, coming to Copacabana Beach may mean tragedy for one stray penguin, but not for its colony as a whole or for the Copacabana neighborhood.

Recognition of these links, which are multi-scale, historical, asymmetrical, and complex, requires interdisciplinary and innovative approaches. In this and in various other cases, it is necessary to incorporate theories, methodologies, and analytical techniques from outside the field of Public Health. Importantly, these processes take place in a global context not only of climate change, but also of political, social, and economic changes. The combination of precarious sanitation, poverty, population aging, and restrictions on access to health services can aggravate the effects of climate change on health 3 .

Finding a penguin in Copacabana today is so trivial that it is not worth even a note in a scientific journal. Progress is needed in methods and theories to explain the processes under way in order to help protect the population's health and the health of the environment. The choice of climate change as the theme for the cover photos on the 2015 editions of $\mathrm{Ca}$ dernos de Saúde Pública highlights the urgency of this debate and the openness of Public Health to new scientific approaches.

Christovam Barcellos

Instituto de Comunicação e Informação Científica e Tecnológica em Saúde, Fundação Oswaldo Cruz, Rio de Janeiro, Brasil.

xris@fiocruz.br

1. Intergovernmental Panel on Climate Change. Climate change 2013: the physical science basis. http:// www.ipcc.ch/report/ar5/wg1 (accessed on 23/ Dec/2014).

2. Nordell B. Thermal pollution causes global warming. Glob Planet Change 2003; 38:305-12.

3. McMichael AJ. Globalization, climate change, and human health. N Engl J Med 2013; 368:1335-43. 